\title{
Education Policy, Growth and Welfare
}

\author{
Nikos Benos ${ }^{1}$ \\ Centre of Planning and Economic Research, Athens
}

February 14, 2007

${ }^{1}$ Address for Correspondence: Nikos Benos, Centre of Planning and Economic Research, 11 Amerikis Street, 10672, Athens, Greece. Tel: +30-2103676353. Fax: +302103611136, +30-2103630122. E-mail: benos@kepe.gr 


\begin{abstract}
This paper studies the general equilibrium implications of two types of education policy in an overlapping generations model. We examine vouchers, which augment inherited private education spending, and public investment on economy-wide human capital, that provides externalities to individual human capital accumulation. The government determines jointly the tax rate and the allocation of tax revenues among the two types of education policy. The optimal division of public spending between the education policy instruments and the associated tax rate depend on the elasticities of human capital accumulation with regard to vouchers and public investment on economy-wide human capital.

Keywords: National government expenditures and education, educational finance, economic development.

JEL classification: H520, I220, O100.

Acknowledgements: I would like to thank M. Haliasos, I. Holezas, A. Kontogiorgis, T. Palivos, A. Philippopoulos, R. Stiegert, the anonymous referees, seminar participants at the University of Ioannina, University of Cyprus, Centre of Planning and Economic Research, Athens and conference participants at the 8th International Conference on Macroeconomic Analysis and International Finance in Rethymno, Greece and the Conference on New Developments in Macroeconomic Modelling and Growth Dynamics in Faro, Portugal for helpful comments and suggestions. All errors are mine.
\end{abstract}




\section{Introduction}

In Europe, North America and other countries, there is an ongoing debate on potential ways of financing activities that have public good characteristics and involve positive externalities, since competitive equilibria are typically inefficient in such cases.

We focus on education policy, because human capital accumulation has been identified as a fundamental source of long-run growth (Lucas, 1988) and income inequality (Glomm-Ravikumar, 1992) in modern economies and we have seen significant government intervention in the funding and provision of education worldwide (Gradstein-Justman, 2000). Education can also be viewed as a mechanism of intergenerational transfers, since it typically takes place at the beginning of the life cycle and it is financed by resources transfered from the old geneneration. ${ }^{1}$ These transfers are altruistically motivated, but affect economic growth, income distribution and welfare through their impact on human capital accumulation (De la Croix-Michel, 2002).

We use an overlapping generations model where human capital is the engine of growth. Private and public education spending coexist, while other work analyzes the private and public education regimes separately (Glomm-Ravikumar, 1992, Zhang, 1996, Cardak, 1999). We also use a richer human capital accumulation specification than other studies (Kaganovich-Zilcha, 1999, Cardak, 2004b) including time devoted to education, two forms of public education spending, private education expenditures and parental human capital. Furthermore, private education transfers are directly incorporated in the utility function and agents put different weight to each of the utility components (the weights are the same for all agents) in contrast with most of the literature (Zhang, 1996, Glomm-Ravikumar,

\footnotetext{
${ }^{1}$ Roughly $5 \%$ of GDP is transferred to the young generation through public education in the OECD countries.
} 
2001). The formulation of both utility and human capital accumulation functions guarantees that our analysis is not affected by scale effects which are ambiguous empirically (Barro-Sala-i-Martin, 2004). Finally, we endogenize the tax rate, which is sometimes taken as exogenous (Kaganovich-Zilcha, 1999, Cardak, 2005).

Our basic result is that the optimal allocation of public spending between education vouchers and expenditures on economy-wide human capital, which create externalities for private human capital, as well as the optimal tax rate depend exclusively on the elacticities of human capital accumulation with respect to the two education policy instruments.

This work is related to three strands of literature on: a) human capital accumulation as an engine of growth (Azariadis-Drazen, 1990); b) alternative ways of financing education (Epple-Romano, 1998, Meier, 2000, Soares, 2003); c) widespread public provision and financing of education as a way to indoctrinate and instill social norms and values e.g reducing the rent-seeking incentives between competitive groups of heterogeneous agents (Gradstein-Justman, 2000, 2002, 2005).

The paper is organized as follows. Section 2 solves for the competitive decentralized equilibrium. Section 3 studies optimal economic policy. Section 4 examines the dynamics of the model. Section 5 investigates the model further employing numerical methods. Section 6 concludes the paper.

\section{The economy and competitive equilibrium}

\subsection{Household behaviour}

Consider an overlapping generations economy populated by $N$ two-period-lived agents. Each generation consists of identical individuals, so it is characterized by a representative agent (symmetric equilibria). ${ }^{2}$ In the second period of life each

\footnotetext{
${ }^{2}$ The solution concept of symmetric equilibria has been widely used in both the public economics and game-theoretic literatures (Persson-Tabellini, 1994).
} 
individual gives birth to one child, therefore population growth is zero.

Agents derive utility from leisure when young and consumption and education quality (education spending) ${ }^{3}$ passed on to the next generation when old. This formulation is based on Glomm-Ravikumar (1992). So, the first linkage between generations is education spending bequests, which reflect human capital-inclined altruism on behalf of the parents and is referred in the literature as "joy of giving" (or "warm glow"), since parents have a taste for giving to their descendants. ${ }^{4}$

The second channel through which parents and children are connected is the stock of parental human capital, which affects children's learning, because a young individual inherits partially the human capital of the parents, i.e there is intergenerational transmission of ability, knowledge and skills within the family that does not work through formal schooling. Parental human capital might also affect children's human capital through the quality of parental tutoring (Belzil-Hansen, 2003, Restuccia-Urrutia, 2004). So, the more educated parents are, the more help they are likely to give to their offspring and the more educated the latter are likely to be.

Also, one unit of time is available to each individual in every period. During the first period, time is allocated to leisure and schooling, while in the second period all time is supplied in the labour market. Higher schooling in the first period results in lower leisure in the same period, but higher human capital (income) in the second period, so there is a trade-off between income and leisure.

Furthermore, we assume that private human capital stock is augmented by the

\footnotetext{
${ }^{3}$ Education quality received by the children is assumed to be determined solely by parental education spending. So, we will use the terms education quality and (parental) education spending (expenditure) interchageably from now on. The term is used in the same way as in Glomm-Ravikumar (1992).

${ }^{4}$ Generally, reasons for bequests are parental altruism, provision of incentives such that the descendants behave according to what parents believe is appropriate and accidental death of retired individuals who are not able to buy actuarially fair annuities. Besides that, in the absence of a bequest motive it would be difficult to explain why even very wealthy individuals maintain large asset balances at death (Azariadis, 1993).
} 
government through: a) public education expenditures, which provide economywide externalities to individual human capital accumulation, on e.g libraries, schools, teachers' and university professors' salaries and training (GH) (Papke, 2005); b) education vouchers complementing inherited parental spending on schooling (EV), e.g student scholarships, teaching and research assistantships or money permitting parents to send their children to private schools. So, GH is expenditure targeted at groups of students, while EV is individual-specific and uniform, i.e not contigent on income, performance etc. Spending is financed by a distortionary income tax. Both GH and EV work as inputs to private human capital formation besides private inputs. An interpretation of the simultaneous presence of private and public factors in human capital accumulation (they are complements), is that the majority of public education spending finances primary and secondary education, while most private expenditure finances preschool/tertiary education and on the job-training. (Blankenau-Simpson, 2004). ${ }^{5}$

In a nutshell, individual human capital accumulation depends on time devoted to schooling, parental education spending, government expenditures on education vouchers, direct public education spending and parental stock of human capital.

Events take place in two stages. First, a centralized fiscal authority chooses the tax rate and the allocation of the associated revenues among the two types of education policy. Second, private agents choose consumption, education spending on their children and leisure (therefore time devoted to education) taking economic policy as given. We solve the problem backwards.

So, the representative agent born in period $t$ chooses leisure when young $\left(n_{t}\right)$, consumption when old $\left(c_{t+1}\right)$ and education expenditures passed on to the next generation $\left(e_{t+1}\right)$ taking educational vouchers $\left(v_{t+1}\right)$, public investment, which provides economy-wide externalities to individual human capital accumulation

\footnotetext{
${ }^{5}$ For an analysis of the effects of policy in a similar framework, see Lin (2003).
} 
$\left(\bar{G}_{t+1}\right)$ and the income tax rate $(\tau)$ as given to maximize the lifetime utility function:

$$
U=\alpha \ln \left(n_{t}\right)+\ln \left(c_{t+1}\right)+b \ln \left(e_{t+1}\right)^{6}
$$

subject to

$$
\begin{aligned}
(1-\tau) h_{t+1} & =c_{t+1}+e_{t+1} \\
h_{t+1} & =A\left(1-n_{t}\right)^{\beta}\left(e_{t} v_{t+1}\right)^{\gamma} \bar{G}_{t+1}^{\zeta} h_{t}^{\delta}
\end{aligned}
$$

where $n_{t} \in[0,1],\left(1-n_{t}\right)$ stands for time devoted to education in period $t, h_{t+1}$ is individual human capital in $t+1$. Also, $h_{t}$ and $e_{t}$ are predetermined and stand for parental human capital and inherited private education spending in period $t .^{7}$

The last element of the utility function reflects ad hoc altruism, i.e "joy of giving". The welfare from leaving a bequest depends on the size of the bequest and the degree of parental altruism towards children $(b)$. Parameter $\alpha$ represents preference for leisure. These parameters are assumed constant over time, since they pass from parents to children, i.e preferences are transmitted across generations.

Given that agents supply one unit of labour inelastically in period $t+1, h_{t+1}$ stands for income and the wage rate. Equation (2) is the budget constraint of the representative household and states that net human capital (disposable income)

\footnotetext{
${ }^{6}$ The consumption of the children is included in parental consumption.

${ }^{7}$ Regarding human capital accumulation, empirical studies show that the quality of education, measured e.g by the student/teacher ratio, term length or relative pay of teachers, influences positively the rate of return of individuals to education, therefore their future income. Also, empirical work shows a positive correlation between parental knowledge and child performance in school (Glomm-Ravikumar, 1992), parental schooling and children's schooling (Plug, 2004). In our paper, human capital is the only source of income, therefore modelling human capital investment as a function of parents' human capital seems reasonable. Furthermore, time spent on human capital investment is expected to have a positive effect on school performance. However, there is no conclusive evidence on the form of the production function for human capital (De La Croix-Michel, 2002).
} 
is devoted to consumption and education bequests to the descendants. Relation (3) is a Cobb-Douglas production function for human capital, where $A>0$ is a technological parameter that measures total factor productivity in the human capital formation technology and is affected by the organization of schools, attitudes to learning etc. Also, $\beta, \gamma, \delta, \zeta \in(0,1)$ exhibit the elacticities of the learning process with regard to time devoted to learning, inherited private education spending and education vouchers, parental human capital and government spending on economy-wide human capital respectively, so that all factors exhibit diminishing returns.

Conditions (2) and (3) imply that

$$
c_{t+1}+e_{t+1}=(1-\tau) A\left(1-n_{t}\right)^{\beta}\left(e_{t} v_{t+1}\right)^{\gamma} \bar{G}_{t+1}^{\zeta} h_{t}^{\delta}
$$

The first-order conditions give: ${ }^{8}$

$$
\begin{gathered}
n_{t}=\frac{\alpha}{\alpha+(1+b) \beta} \\
c_{t+1}=\frac{1-\tau}{1+b} h_{t+1} \\
e_{t+1}=\frac{b(1-\tau)}{1+b} h_{t+1} \\
h_{t+1}=A\left[\frac{(1+b) \beta}{\alpha+(1+b) \beta}\right]^{\beta}\left(\frac{b(1-\tau)}{1+b} h_{t} v_{t+1}\right)^{\gamma} \bar{G}_{t+1}^{\zeta} h_{t}^{\delta}
\end{gathered}
$$

Equation (5) means that the equilibrium time devoted to learning/leisure is constant over time and independent of parental human capital and education

\footnotetext{
${ }^{8}$ The second-order conditions are also satisfied.
} 
expenditures, since the income and substitution effects of changes in $e_{t}$ and $h_{t}$ balance each other perfectly. ${ }^{9} \quad$ The stronger the preference over leisure $(\alpha)$ and the smaller the degree of parental altruism towards children $(b)$ as well as the elasticity of human capital accumulation with regard to time spent on education $(\beta)$, the higher is optimal leisure and the lower the learning time. Also, income, consumption and education transfers depend positively on learning efficiency $(A)$ and parental human capital $\left(h_{t}\right)$ and negatively on leisure preferences $(\alpha)$ by $(6)$ (8).

\subsection{Government budget constraint}

The government runs a balanced budget. It uses revenues from proportional income taxation and allocates them between two types of spending, educational vouchers $\left(v_{t+1}\right)$ and average direct expenditures on economy-wide human capital $\left(\bar{G}_{t+1}\right)$.

Given $N$ symmetric private agents, the government budget constraint is:

$$
N v_{t+1}+N \bar{G}_{t+1}=\tau H_{t+1}=\tau N h_{t+1}
$$

Without loss of generality, we denote the shares of tax revenues financing $N v_{t+1}, N \bar{G}_{t+1}$ as $k_{1}, k_{2}$, where

$$
0<k_{2}=1-k_{1}<1
$$

respectively. Thus (9) can be decomposed into:

$$
\begin{gathered}
N v_{t+1}=k_{1} \tau N h_{t+1} \\
N \bar{G}_{t+1}=\left(1-k_{1}\right) \tau N h_{t+1}
\end{gathered}
$$

\footnotetext{
${ }^{9}$ This holds due to log-linear preferences.
} 
Equations (9)-(12) imply that economic policy is summarized by $\left(k_{1}, \tau\right)$, where $0<\tau<1$.

\subsection{Competitive decentralized equilibrium}

The Competitive Decentralized Equilibrium (CDE) is defined as the set of allocations $\left(n_{t}, c_{t+1}, e_{t+1}, h_{t+1}\right)$ such that: (i) households maximize utility given economic policy; (ii) markets clear; (iii) constraints are satisfied.

Using (11)-(12), we get the following:

$$
\begin{gathered}
v_{t+1}=k_{1} \tau h_{t+1} \\
\bar{G}_{t+1}=\left(1-k_{1}\right) \tau h_{t+1}
\end{gathered}
$$

Proposition 1 By (5)-(8) and (13)-(14) in a symmetric competitive decentralized equilibrium (given any economic policy), optimal leisure, consumption, education transfers, individual human capital are respectively:

$$
\begin{gathered}
n_{t}=\frac{\alpha}{\alpha+(1+b) \beta} \\
c_{t+1}=A^{\frac{1}{1-\gamma-\zeta}}\left[\frac{(1+b) \beta}{\alpha+(1+b) \beta}\right]^{\frac{\beta}{1-\gamma-\zeta}}\left(b k_{1}\right)^{\frac{\gamma}{1-\gamma-\zeta}}\left(1-k_{1}\right)^{\frac{\zeta}{1-\gamma-\zeta}}\left(\frac{1-\tau}{1+b}\right)^{\frac{1-\zeta}{1-\gamma-\zeta}} \\
\tau^{\frac{\gamma+\zeta}{1-\gamma-\zeta}} h_{t}^{\frac{\gamma+\delta}{1-\gamma-\zeta}} \\
e_{t+1}=A^{\frac{1}{1-\gamma-\zeta}}\left[\frac{(1+b) \beta}{\alpha+(1+b) \beta}\right]^{\frac{\beta}{1-\gamma-\zeta}} k_{1}^{\frac{\gamma}{1-\gamma-\zeta}}\left(1-k_{1}\right)^{\frac{\zeta}{1-\gamma-\zeta}}\left[\frac{b(1-\tau)}{1+b}\right]^{\frac{1-\zeta}{1-\gamma-\zeta}} \\
\tau^{\frac{\gamma+\zeta}{1-\gamma-\zeta}} h_{t}^{\frac{\gamma+\delta}{1-\gamma-\zeta}}
\end{gathered}
$$




$$
\begin{aligned}
& h_{t+1}=A^{\frac{1}{1-\gamma-\zeta}}\left[\frac{(1+b) \beta}{\alpha+(1+b) \beta}\right]^{\frac{\beta}{1-\gamma-\zeta}}\left[\frac{b(1-\tau) k_{1}}{1+b}\right]^{\frac{\gamma}{1-\gamma-\zeta}}\left(1-k_{1}\right)^{\frac{\zeta}{1-\gamma-\zeta}} \\
& \tau^{\frac{\gamma+\zeta}{1-\gamma-\zeta}} h_{t}^{\frac{\gamma+\delta}{1-\gamma-\zeta}}
\end{aligned}
$$

In the next section we endogenize $v_{t+1}, \bar{G}_{t+1}$ and $\tau$.

\section{Optimal economic policy and general equilib- rium}

To endogenize economic policy, it is sufficient to determine the independent policy instruments $\left(k_{1}, \tau\right)$. A centralized fiscal authority maximizes the utility of the representative old agent choosing the fraction of tax revenues devoted to educational vouchers $\left(k_{1}\right)$ and a uniform tax rate $(\tau)$. This authority acts as a benevolent Stackelberg leader vis-a-vis the private sector by taking into account the competitive decentralized equilibrium.

Substituting (15)-(18) into (1) and differentiating with respect to $\left(k_{1}, \tau\right)$ the first-order conditions are the following:

$$
\begin{gathered}
(1+b)\left[\frac{\gamma}{1-\gamma-\zeta} k_{1}^{-1}-\frac{\zeta}{1-\gamma-\zeta}\left(1-k_{1}\right)^{-1}\right]=0 \\
\frac{-(1+b)}{1-\gamma-\zeta}\left[(1-\zeta)(1-\tau)^{-1}-(\gamma+\zeta) \tau^{-1}\right]=0
\end{gathered}
$$

By solving (19)-(20) for the optimal policy vector $\left(k_{1}, \tau\right)$, we get: ${ }^{10}$

$$
\begin{gathered}
k_{1}=\frac{\gamma}{\gamma+\zeta} \\
\tau=\frac{\gamma+\zeta}{1+\gamma}
\end{gathered}
$$

\footnotetext{
${ }^{10}$ The second-order conditions of the problem hold.
} 
Therefore, the portion of tax revenues devoted to education vouchers $\left(k_{1}\right)$ and the optimal (second-best) tax rate $(\tau)$ are constant over time due to log-linear preferences and Cobb-Douglas learning technology. The former depends positively on the elacticity of future human capital with regard to educational vouchers $(\gamma)$ and negatively on the elasticity of human capital with respect to average public spending, which creates economy-wide externalities to individual human capital $(\zeta)$. These results are expected, since the more productive vouchers are in terms of human capital accumulation, the higher share of public spending will be optimal to be devoted to them, while if the same holds for $\bar{G}_{t+1}$, it is optimal to spend a higher share on this type of expenditure, implying a lower fraction going to vouchers.

On the other hand, the optimal tax rate is a positive function of $\gamma, \zeta$, which makes sense because if either of the components of public spending contributes more to human capital accumulation, it is optimal to increase total expenditure to accomodate higher spending for the relevant type of education policy and this makes a higher tax rate necessary.

\section{Dynamics}

In this section, we study the dynamics of human capital accumulation. So, combining (18), (21)-(22), we get:

$$
h_{t+1}=B h_{t}^{\frac{\gamma+\delta}{1-\gamma-\zeta}}
$$

where

$$
\begin{array}{r}
B=A^{\frac{1}{1-\gamma-\zeta}}\left[\frac{(1+b) \beta}{\alpha+(1+b) \beta}\right]^{\frac{\beta}{1-\gamma-\zeta}}\left[\frac{b \gamma(1-\zeta)}{(1+b)(1-\gamma)(\gamma+\zeta)}\right]^{\frac{\gamma}{1-\gamma-\zeta}}\left(\frac{\zeta}{\gamma+\zeta}\right)^{\frac{\zeta}{1-\gamma-\zeta}} \\
\left(\frac{\gamma+\zeta}{1+\gamma}\right)^{\frac{\gamma+\zeta}{1-\gamma-\zeta}}(24)
\end{array}
$$


From this law of motion, we establish conditions for the existence and uniqueness of steady-state human capital as follows:

i) If $(2 \gamma+\delta+\zeta) \in(0,1)$, the economy converges monotonically to a unique steady-state human capital $h_{s}=B^{\frac{1-\gamma-\zeta}{1-2 \gamma-\delta-\zeta}}$.

ii) If $2 \gamma+\delta+\zeta=1$, the human capital of every family exhibits long-run or endogenous growth/decay at rate $B-1$. One can distinguish three subcases:

a) $B=1$. Then $h_{t+1}=h_{t}$, therefore the representative agent stays at his $/$ her initial human capital.

b) $B<1$. There is monotonic convergence to a steady-state human capital level equal to zero.

c) $B>1$. All families experience long-run growth at rate $B-1$.

iii) If $2 \gamma+\delta+\zeta>1$, the representative family may converge to one of two steady-state human capital levels equal to 0 and $B^{\frac{1-\gamma-\zeta}{1-2 \gamma-\delta-\zeta}}$, depending on initial conditions, i.e. the equilibria are unstable. Specifically, if $h_{0}<B^{\frac{1-\gamma-\zeta}{1-2 \gamma-\delta-\zeta}}$, then $h_{t} \rightarrow 0$, when $h_{0}>B^{\frac{1-\gamma-\zeta}{1-2 \gamma-\delta-\zeta}}, h_{t} \rightarrow \infty$ and if $h_{0}=B^{\frac{1-\gamma-\zeta}{1-2 \gamma-\delta-\zeta}}$, human capital rests at its initial condition.

The cases of primary economic interest are i) and iic) and the conclusions may be summarized as follows:

Proposition 2 a) If $(2 \gamma+\delta+\zeta) \in(0,1)$, the representative family's human capital converges monotonically to the steady-state level $B^{(1-\gamma-\zeta) /(1-2 \gamma-\delta-\zeta)}$; b) If $2 \gamma+\delta+\zeta=1$ and $B>1$ the agents' human capital exhibits long-run growth at rate $B-1$.

As a result, the dynamics of our economy allow for a variety of growth paths depending on parameter values, including the neoclassical and endogenous growth as subcases. 


\section{Numerical analysis}

\subsection{Neoclassical growth}

\subsubsection{Steady-state}

Having computed the shares of direct education spending and education vouchers in total government expenditure and the associated income tax rate analytically, we conduct a sensitivity analysis of the endogenous variables of the model with regard to the model's parameters, i.e $\alpha, b, \beta, \gamma, \delta, \zeta$, when the economy is in the steady-state.

The baseline values for $\alpha, b, \beta, \gamma, \delta, \zeta$ are chosen based, among others, on Acemoglou-Angrist (1999), Glomm-Ravikumar (2001), Soares (2003), PatrinosPsacharopoulos (2004), Cardak (2004b). The benchmark values for $\alpha, \beta$ (strength of preferences over leisure and elasticity of human capital accumulation with regard to time spent on education respectively) are such that the optimal learning time is in line with estimates of time devoted to schooling work. Also, $\alpha, b$ (the latter corresponds to preferences for education bequests) are selected so that the agents put weights on consumption, leisure and human capital bequests equal to $60 \%, 25 \%$ and $15 \%$ respectively and the weights are normalized so that the coefficient of consumption equals 1 . The benchmark values for the elacticities of human capital accumulation with regard to vouchers, average direct public education spending and parental human capital $(\gamma, \zeta, \delta$ respectively) correspond to the average estimates provided in the literature except for the latter for which the range of values used is so wide that we assign a relatively low value to satisfy the condition for neoclassical growth (section 4, case (i)). Furthermore, A (total factor productivity of human capital accumulation) is set such that the annual growth rate is positive. Initial (period 0) human capital $\left(h_{0}\right)$ was set arbitrarily. As a result, the baseline parameter values are $\alpha=0.42, b=0.25, \beta=0.2, \gamma=0.1$, 
$\delta=0.3, \zeta=0.1, A=5, h_{0}=3$.

For these values, learning time is $37.3 \%$ of the total time endowment and the tax rate equals $18.2 \%$. The shares of vouchers and direct education expenditures, that create externalities on economy-wide human capital, in total spending are $50 \%$ each. This is expected, because the two types of spending are assumed to be equally productive.

Now we perform a sensitivity analysis to check how robust are the benchmark results for plausible parameter configurations. The ranges of values are such that $\alpha \in[0.08,0.58], b \in[0.08,0.58], \beta \in[0.1,0.3], \gamma \in[0.01,0.2], \delta \in[0.2,0.4]$, $\zeta \in[0.01,0.2]$ and are broad enough to include most empirically plausible values.

As a result, the optimal time devoted to education ranges from $15.7 \%$ to $86.6 \%$, the share of vouchers in total spending is between $4.8 \%$ and $95.2 \%$ and the second-best tax rate can be as low as $2 \%$ and as high as $33.3 \%$.

Regarding steady-state human capital $\left(h_{s}\right)$, as $b$ rises, learning time, private and public education spending increase and so does human capital. When $\beta$ increases, the marginal contribution of schooling time to human capital accumulation declines and human capital decreases. Also, as $\gamma, \zeta$ get higher, human capital initially decreases and later increases, because the tax rate is a positive function of $\gamma, \zeta$ and the distortionary tax effect outweighs the positive effect of education spending on human capital for low $\gamma, \zeta$, while the opposite happens for high parameter values. Finally, when $\delta$ gets higher, parental human capital becomes more productive resulting in higher income. Consumption and private education expenditures exhibit the same behaviour qualitatively with human capital, since they both represent a fraction of income.

Turning to the policy instruments, stronger preferences over education bequests (b) imply a higher income, therefore a larger voucher in the steady-state $\left(v_{s}=k_{1} \tau h_{s}\right)$. A higher elasticity of human capital accumulation with respect 


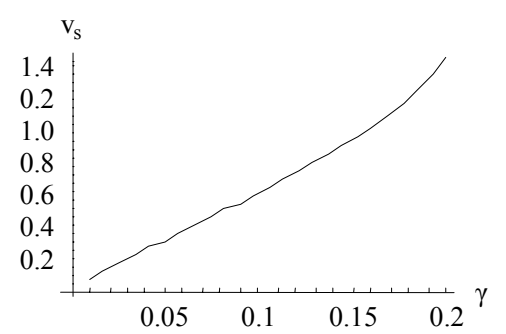

$\overline{\mathrm{G}}_{\mathrm{s}}$

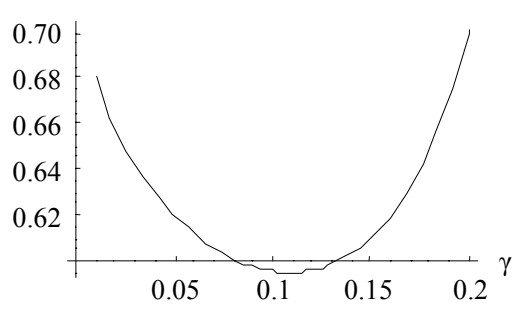

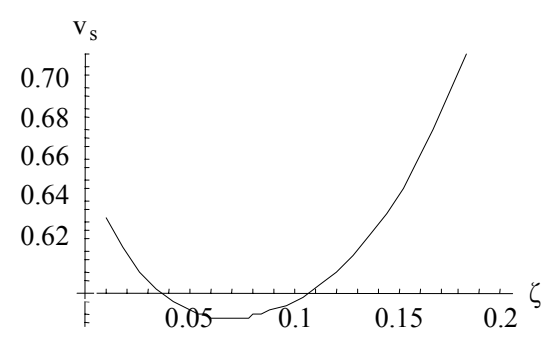

$\overline{\mathrm{G}}_{\mathrm{s}}$

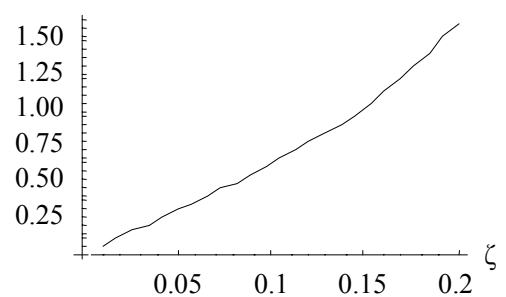

Figure 1: Sensitivity of steady-state vouchers, direct education spending wrt $\gamma, \zeta$

to learning time $(\beta)$ lowers human capital, therefore vouchers. Besides these, the more sensitive human capital accumulation with respect to vouchers, i.e the higher $\gamma$ is, human capital declines initially and then rises, the fraction devoted to vouchers $\left(k_{1}\right)$ and the tax rate increase, so the fraction spent on direct education spending $\left(1-k_{1}\right)$ falls. Furthermore, $k_{1}$ is a negative function of $\zeta$. As a result, $v_{s}$ rises with regard to $\gamma$ and displays a $\mathrm{U}$-shaped relationship with $\zeta$, while the opposite happens with steady-state $\bar{G}\left(\bar{G}_{s}=\left(1-k_{1}\right) \tau h_{s}\right)$. Also, a higher elasticity of future human capital with regard to parental human capital $(\delta)$ increases human capital and vouchers (see figure 1 for representative results).

Furthermore, a welfare analysis is useful even in the context of a representative agent model as ours, since it shows the impact of changes in the model's parameters on utility, which government aims at maximizing through policy. In this context, a higher $b$ increases consumption, education bequests and their weight on welfare, while it reduces leisure and its weight on welfare. The net welfare effect is positive. Also, a higher $\beta$ reduces all components of utility, therefore total utility. 

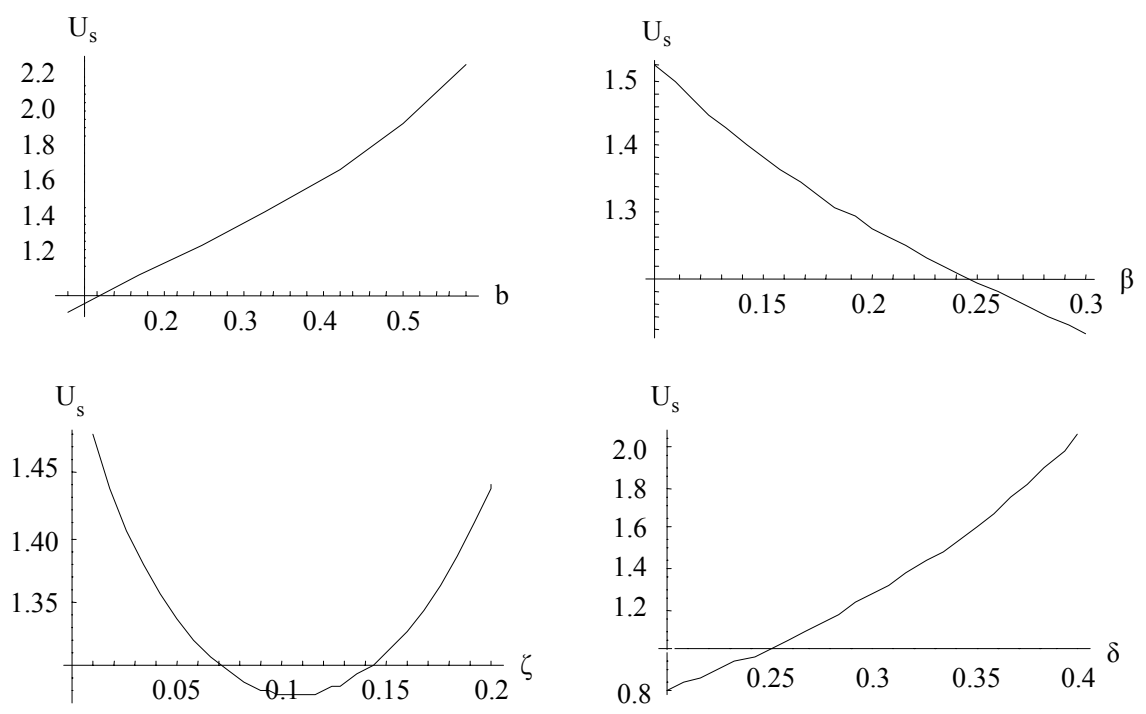

Figure 2: Sensitivity of steady-state welfare wrt $b, \beta, \zeta, \delta$

Furthermore, the more effective direct education expenditures and vouchers are in stimulating human capital accumulation, i.e the higher $\gamma, \zeta$ are, consumption and education bequests decline up to a point and increase afterwards, resulting in a U-shaped relation between $\gamma, \zeta$ and welfare. Finally, a higher elasticity of future human capital with regard to parental human capital $(\delta)$ implies higher consumption and education expenditures, consequently welfare (figure 2).

So, economies with high degree of education-inclined altruism towards the young are expected to have high vouchers and direct education spending. Also, countries with education technology sensitive to learning time will be characterized by low vouchers and direct education expenditures, while the opposite holds for economies with high elasticity of human capital with respect to parental human capital. Furthermore, countries with efficient public and private education sectors, will be experiencing high education spending of both types. 


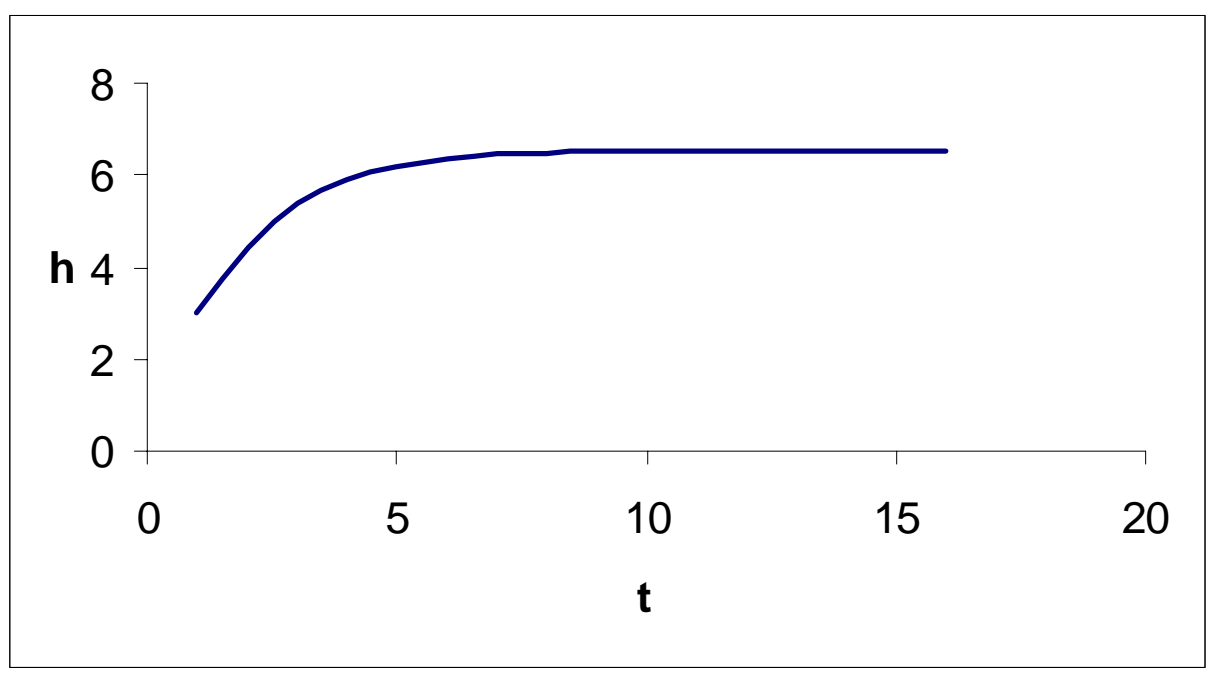

Figure 3: Time path of human capital

\subsection{Transitional dynamics}

To explore our model further, we study the transitional dynamics of human capital and welfare. We conduct simulations using the benchmark parameter values, i.e $\alpha=0.42, b=0.25, \beta=0.2, \gamma=0.1, \delta=0.3, \zeta=0.1, A=5, h_{0}=3$, assuming each time period of individuals' lives lasts 35 years.

In this context, human capital (income) reaches a steady-state $h_{s}=6.52$ in 11 periods with an average growth of $0.2 \%$ per year (figure 3 ), while welfare converges to the steady-state in only 7 periods (figure 4). So, consumption and education expenditure dynamics increase the welfare convergence rate, since steady-state welfare is attained faster than what human capital dynamics alone would imply.

\subsection{Endogenous growth}

We now study the case where the economy displays endogenous growth, i.e $\gamma=$ $0.2, \delta=0.4, \zeta=0.2$ (see section 4 , case ii)c). Keeping the other parameters at the baseline values, i.e for $\alpha=0.42, b=0.25, \beta=0.2, A=5, h_{0}=3$, optimal time 


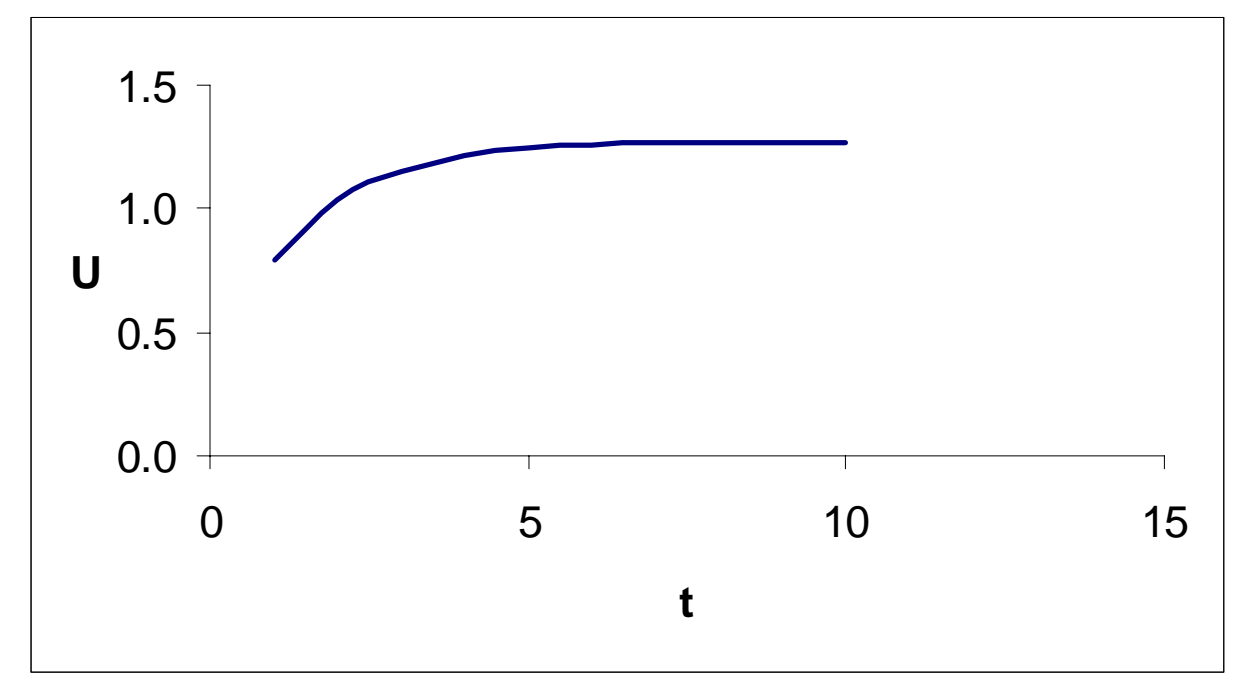

Figure 4: Time path of welfare

devoted to education and its range remain the same as in the neoclassical growth case $(37.3 \%$ and $[15.7 \%, 86.6 \%]$ respectively) since they do not depend on these paramaters, but the tax rate increases to $33.3 \%$ from $18.2 \%$, due to the higher $\gamma, \zeta$ values. The shares of vouchers and direct education spending in government expeditures do not change, they are $50 \%$ each, because the rise in $\gamma, \zeta$ compared to the benchmark case is equiproportionate.

However, the higher elasticities of human capital with respect to vouchers, parental human capital and average public direct education spending have serious growth implications, i.e the average yearly growth rate increases from $0.2 \%$ to $1.4 \%$, and ranges from $0.5 \%$ to $2.7 \%$ depending on $\alpha, b, \beta$ for given $\gamma, \delta, \zeta$. So, the endogenous growth rates are much closer to the long-run performance of modern economies than the neoclassical growth rate, which points to the possibility that $\gamma, \delta, \zeta$ may in reality be higher than they are thought to be. Finally, the rise in human capital increases vouchers, direct public education expenditures, private education spending and consumption, therefore welfare. 
As a result, economies with more efficient public/private education sectors and stronger intergenerational human capital linkages will be characterized by higher taxes, public and private education expenditures, consumption, growth and welfare.

\section{Conclusions}

In this paper we examined the implications of two types of education policy, vouchers (EV) and direct investment on economy-wide human capital (GH) in a general equilibrium setting. We focused on education policy, because human capital accumulation is a fundamental source of long-run growth in modern economies and government intervention in education is widespread.

We found that the optimal allocation of government revenues between EV and $\mathrm{GH}$ and the tax rate depend exclusively on the elasticities of human capital accumulation with respect to $\mathrm{EV}(\gamma)$ and $\mathrm{GH}(\zeta)$. For the baseline parameter values, it was shown that the government should equally divide education spending between $\mathrm{EV}$ and $\mathrm{GH}$ and finance it by a modest income tax.

According to the sensitivity analysis performed, vouchers depend positively on $\gamma$ and exhibit a U-shaped relationship with $\zeta$, while the opposite holds for direct education expenditures. Also, the optimal tax rate is a positive function of both parameters. As for welfare, it depends positively on human capital-inclined parental altruism $(b)$ and the sensitivity of human capital with respect to parental human capital $(\delta)$, negatively on learning time efficiency $(\beta)$ and exhibits a Ushaped relation with $\gamma, \zeta$.

We close with possible extensions. First, we could examine an economy where the individuals in each generation are heterogeneous, allowing for more elaborate education policies, e.g means-tested vouchers, which would allow us to study the impact of education policies on income distribution. Furthermore, we might study 
the case of progressive income taxation and model uncertainty with respect to the characteristics of human capital accumulation, e.g life length and innate abilities. We leave these extensions for the future. 


\section{References}

Acemoglou, D., Angrist, J. (1999): "How Large Are Social Returns to Education? Evidence From Compulsory Schooling Laws." NBER working paper 7444: 1-43.

Azariadis, C. (1993): Intertemporal Macroeconomics. Boston: Blackwell Publishers.

Azariadis, C., Drazen, A. (1990): "Threshold Externalities in Economic Development." Quarterly Journal of Economics 105, 2: 501-526.

Barro, R.J., Sala-i-Martin, X. (2004): Economic Growth. Cambridge, Massachusetts, London, England: MIT Press.

Belzil, C. , Hansen, J. (2003): "Structural Estimates of the Intergenerational Education Correlation." IZA discussion paper 973, December: 1-26.

Blankenau, W.F, Simpson, N.B. (2004): "Public Education Expenditures and Growth." Journal of Development Economics, 73: 583-605.

Cardak, B.A. (2005a): "Education Vouchers, Growth and Income inequality." Macroeconomic Dynamics, 9: 98-121.

Cardak, B.A. (2004b): "Education Choice, Neoclassical Growth and Class Structure." Oxford Economic Papers, 56: 643-666.

Cardak, B.A. (1999): "Heterogeneous Preferences, Education Expenditures and Income Distribution." Economic Record, 75, 228, 63-76.

De la Croix, D., Michel, P. (2002): A Theory of Economic Growth: Dynamics and Policy in Overlapping Generations. Cambridge: Cambridge University Press. 
Epple, D., Romano, R.E. (1998): "Competition Between Private and Public Schools, Vouchers and Peer-group Effects." American Economic Review, 88, 1: 33-62.

Glomm, G., Ravikumar, B. (2001): "Human Capital Accumulation and Endogenous Public Expenditures." Canadian Journal of Economics, 34, 3: 807-826.

Glomm, G. Ravikumar, B. (1992): "Public Versus Private Investment in Human Capital: Endogenous Growth and Income Inequality." Journal of Political Economy, 100, 4: 818-834.

Gradstein, M., Justman, M. (2005): “The Melting Pot and School Choice.” Journal of Public Economics, 89, 5-6: 871-896.

Gradstein, M., Justman, M. (2002): "Education, Social Cohesion, and Economic Growth." American Economic Review, 92, 4: 1192-1204.

Gradstein, M., Justman, M. (2000): "The Political Economy of Education. Human Capital, Social Capital and Public Schooling." European Economic Review, 44: 879-890.

Kaganovich, M., Zilcha, I. (1999): "Education, Social Security and Growth." Journal of Public Economics, 71: 289-309.

Lin, S. (2003): "The Effect of Public Transfers on Physical and Human Capital Accumulation." Public Finance Review, 31, 6: 669-693.

Lucas, R.E. (1988): "On the Mechanics of Economic Development." Journal of Monetary Economics, 22: 3-42.

Meier, V. (2000): Choosing Between School Systems. CESIfo working paper 389: 1-10. 
Papke, L.E. (2005): "The Effects of Spending on Test Pass Rates: Evidence From Michigan." Journal of Public Economics, 89, 5-6: 821-839.

Patrinos, H.A., Psacharopoulos, G. (2004): "Returns to Investment in Education: A Further Update", Education Economics, 12, 2:111-134.

Persson, T., Tabellini, G. (1994): "Is Inequality Harmful for Growth?" American Economic Review, 84: 599-621.

Plug, E. (2004): "Estimating the Effect of Mother's Schooling on Children's Schooling Using a Sample of Adoptees". American Economic Review, 94, 1: 358368.

Restuccia, D., Urrutia, C. (2004): "Intergenerational Persistence of Earnings: The Role of Early and College Education." American Economic Review, 94, 5: $1354-1378$.

Soares, J. (2003): "Self-interest and Public Funding of Education." Journal of Public Economics, 87: 703-727.

Zhang, J. (1996): "Optimal Public Investments in Education and Endogenous Growth." Scandinavian Journal of Economics, 98, 3: 387-404. 